\title{
CIDADES SUTIS: DISPERSÃO URBANA E DA REDE DE SAÚDE
} MENTAL

\author{
SUBTLE CITIES: THE URBAN AND MENTAL HEALTH DISPERSION
}

Luis Artur Costa

Universidade Federal de Pelotas, Pelotas/RS, Brasil

Tania Mara Galli Fonseca

Universidade Federal do Rio Grande do Sul, Porto Alegre/RS, Brasil

\begin{abstract}
RESUMO
Este artigo pretende problematizar o percurso genealógico que possibilita o atual arranjo entre a cidade de Porto Alegre e sua assistência em saúde mental. Inicia com a cidade e seu Hospital Psiquiátrico São Pedro, constituídos a partir de uma lógica disciplinar que buscava subjetivar corpos e gestos adequados para o trabalho industrial e aos padrões de convivência da civilidade urbana moderna. Vemos então o surgimento de movimentos anômalos a esta geometria, espasmos descentralizantes que vão esboroando as antigas centralidades e seus lócus antes fechados. Através da breve genealogia dos movimentos que tomaram tais espaços, operamos a problematização das transformações nesta cidade e nas atuais práticas de assistência à saúde mental: por um lado, as novas microssegmentações privadas no espaço urbano contemporâneo minando a centralidade urbana da cidade com a dispersão da convivência e, por outro, a atual reforma psiquiátrica, com a descentralização da assistência.
\end{abstract}

Palavras-chave: Reforma Psiquiátrica; urbanismo; genealogia; contemporaneidade.

\begin{abstract}
This work departs from Porto Alegre city situation and its Psychiatric Hospital São Pedro during half century $\mathrm{XX}$, constituted from a centralized disciplinary geometry that intended to subjective adequated bodies and gestures for industrial work and for the conviovility patterns of the urban civility. Departing from this forces configuration, we pass to one genealogy of the first dispersal spasm that took these spaces, making possible their transformation by the actual pratices: in the contemporary urban space with its dispersal privated segmentations, and, by other hand, in the actual psychiatric reform, with the assistance descentralization. Passing by the moment of the Hospital and downtown overcrowding, in order to came to the first practices of emptiness from the urban center and the asylum space centrality, we accompanied the beginnings of the 1980 years, creating the condiction for the reform possibility at Rio Grande do Sul in the 1990 decade.
\end{abstract}

Keywords: Psychiatric Reform; urbanism; genealogy; contemporaneity.

\section{Centralidade disciplinar da modernidade}

Desde seu primeiro grande surto de crescimento na metade do século XIX e da consequente exigência da criação de um espaço que pudesse dar conta dos inumeráveis surtos que advinham do crescimento urbano e suas acelerações jamais vistas por seus nobres cidadãos, a cidade de Porto Alegre e o seu grande Hospício, o São Pedro, receberam vultosos investimentos que tentaram de todas as formas, até ao menos a metade do século XX, guarnecer a ordem e os bons costumes através de um aparato técnico urbanístico e psiquiátrico o qual delineava fronteiras bem definidas entre os civilizados e os não civilizados. Durante a segunda metade do século XIX, a cidade de Porto Alegre, através de sua municipalidade cada vez mais firmemente ancorada no estado que até estas plagas chegava, transformou o aspecto da cidade, estabelecendo uma série de delimitações classificatórias através das quais cada coisa deveria permanecer em seu devido lugar: onde se coloca o lixo, qual a ordem numérica das casas e que casas podem se construir em que lugares, entre outros assuntos, definiram-se então.

Do mesmo modo, o Hospício São Pedro foi transformado desde seu surgimento no final do século XIX até a metade do século XX de modo a incorporar ao seu espaço uma série de especificações técnicas as quais permitiam uma melhor inteligibilização imediata dos fluxos insanos que lá eram alocados para serem recolocados em seu prumo normal. Desde o princípio 
pouco psiquiátrico (quando era administrado por religiosos) até sua real medicalização, o Hospício, assim como sua cidade, passou por um intenso processo de esquadrinhamento, o qual buscava transformá-lo em uma máquina de reforma disciplinar. Segundo uma dinâmica do quadro classificatório, construindo um espaço nosográfico fechado autorreferente, universo segmentado dos demais onde cada tipo tem seu lócus em correlação definida a partir de linhas e colunas que se cruzam na tipificação das coisas e pessoas.

Assim, instituía-se uma lógica binária urbana e psiquiátrica, a qual construía círculos concêntricos fortemente segmentados entre si instituindo uma dialética do dentro e do fora. $\mathrm{O}$ centro da cidade, com os largos investimentos em limpeza, ajardinamento paisagístico, iluminação pública, retirada de antigas casas e cortiços, tornava-se o centro de convivência e sociabilidade dos que eram considerados civilizados, do footing, cafés e confeitarias; fora deste cinturão central eram depositados os botecos e os bordéis, para os arraiais periféricos eram alocados os pobres, negros e proletários, e aos que ousavam furar tal membrana dura, haviam sido construídos não há muito tempo uma diversidade de sítios especiais: Casa de correção, Prisão, Sanatório, Asilo de alienados.

E é nas rebarbas da cidade, em um de seus últimos círculos, que se estabelece outro pequeno círculo desses que serviam à exclusão classificatória: o Hospício São Pedro, o qual, no decorrer de suas décadas, vai ganhando corpo e densidade, abrindo a abrangência de seu círculo e intensificando sua centralidade na atração dos corpos insanos até o espaço interno dos seus muros, tornando-se ao longo do século XX um espaço de prática e produção de saberes médicos, constituindo uma ampla gama de ações capilarizadas pelo seu espaço e do Estado do RS, vindo a sert uma das centrais da civilidade, para onde era enviada a loucura no afã de vê-la anulada pela reforma ou segmentação. O importante nesta máquina não é, ainda, fluir sua ordem a todo tecido capilar de ruelas longínquas na cidade, mas sim seccionar o espaço urbano nestes dois modos, o dentro e o fora, assegurando simetria ao mover-se do central: consagração da lógica centro-periferia como estratégia de segregação.

\section{A primeira falência da centralidade disciplinar}

Se, até a metade do século XX, o centro era um local muito procurado para moradia das altas classes, sendo ocupado por belos palacetes, casarões e servindo de destino ao lazer polido dos cafés e confeitarias, a partir da metade do século ele sofrerá um crescente processo de desvalorização e esvaziamento de residências. Não se trata de um simples abandono e esvaziamento da centralidade urbana, muito antes o contrário: o centro torna-se a tal ponto o centro de convergência de uma variada multidão anônima, que este vértice torna-se por demais agitado para a moradia dos que ali fixavam residência. $\mathrm{O}$ crescimento exponencial da cidade e seus fluxos durante a primeira metade do século XX produziu a abertura de grandes avenidas e o estabelecimento de um intenso intercâmbio comercial. $\mathrm{O}$ centro da cidade de Porto Alegre passou a perder seus galantes ares de passeio e morada de notáveis para tornar-se gradualmente $o$ degradado intercurso comercial da célula urbana.

Em meio a esses novos fluxos que passam a zunir pelas ruas centrais, outros modos de habitá-las iniciam sua formação: a confusão do entorno exige retidão interna. A nova companhia dos automóveis e dos estranhos anônimos exige do pedestre um novo modo de caminhar: o "passo inglês" ou "andar à americana" (Sevcenko, 1998, p.551), passos rápidos e firmes de um corpo ereto e solitário em meio aos demais. É o juvenil fluxo do progresso tomando de assalto aos gestos do homem urbano, o qual já não tem tempo e interesse em passear ociosamente. A cidade, então, não é vista como um campo de possibilidades de encontro para um flanante se desfazer em seu meio, mas sim uma flamejante selva a ser percorrida por um paranoico aventureiro encarcerado em sua individualidade. Cada vez mais os terrenos centrais são comprados por empresas e afins, mais preocupadas com a acessibilidade ao empreendimento do que com a tranquilidade. $O$ prestígio burguês se muda para os bairros que surgem. As famílias abastadas saem do centro na direção das terras altas da Avenida Independência, em uma fuga na direção do leste que segue até hoje, ainda que os sentidos tenham se multiplicado.

O Hotel Majestic nos serve de exemplo para delinear este percurso do centro. Esse hotel, que hospedava pessoas de prestígio, como casais abonados em lua de mel, estudantes filhos de estancieiros do interior e militares, a partir da década de 1950 sofre uma mudança gradual no seu público (Carvalho, 1996). Encravado no que fora a um só tempo a zona mais populosa e chic de POA, passa a receber não mais as tradicionais famílias e a ter seus serviços com uma qualidade de ponta para manter a fidelidade desses dignos clientes, tornando-se, isto sim, o Hotel um atracadouro de mascates, guarida de caixeiros viajantes atraídos pelo crescente comércio estabelecido no centro de POA. Tal processo de degradação se intensifica a partir dos anos sessenta, quando se torna moradia para velhos solitários e jovens solteiros, findando por 
fechar. As famílias com posses fogem do centro da cidade e sua nova (des)ordenação voltada aos velozes fluxos do comércio diurno, e de sua desertificação à noite. Processo que não é exclusivo de POA.

Cria-se na cidade moderna um campo de batalha diário entre os pedestres e os novos veículos automotores. Qualquer percurso exige atenção máxima, concentração, reflexos rápidos, golpe de vista, gestos atléticos e instinto de sobrevivência. A máxima dominante é o 'Sempre alerta!'. (Augusto Malta, sem título, Rio de Janeiro, 1920-1930, citado por Sevcenko, 1998, p.550)

A cidade perde a sua cabeça, mas não completamente. O centro já não se constitui enquanto centralidade total da vida urbana, mas, ainda que os poderosos já lá não morem, lá persistem as sedes dos poderes: os principais comércios, os centros financeiros, as sedes dos poderes políticos e afins. Inicia-se um processo de perda da centralidade na malha urbana de Porto Alegre, com a construção de aglomerados residenciais os quais, no entanto, ainda dependem das idas ao centro para o transcorrer do cotidiano. Essa dispersão pendular se torna possível, em grande parte, por conta dos transportes: em 1927 se deu a primeira Exposição Rio-grandense de Automóveis, a qual fora aclamada como signo da modernidade que alcançava a cidade. Já entre os anos 1950-1975, o número de automóveis particulares cresce 20 vezes, enquanto a população duplica (Faculdade de Arquitetura da UFRGS - FACARQ, 1980), sendo esse processo mais intenso entre 196065 e 1970-75. Aumenta-se a locomoção de um grupo reduzido de pessoas, modificando-se toda a estrutura da cidade em função dessa possibilidade do deslocarse privado. Viadutos e elevadas de escoamento do trânsito do centro para os bairros são construídos, estabelecendo-se este enquanto espaço de passagem. Uma miríade de novos espaços, privados e móveis, transformam os modos espaciais de POA, acelerando-a e alargando-a a partir do aumento na velocidade e facilidade no deslocamento de algumas camadas da população. Será o princípio de uma fragmentação dispersiva que redundará em pequenas segmentações as quais nos apartam do estranho.

Novos bairros formam-se, novos planos diretores ampliam as possibilidades construtivas e as vias radiais são incrementadas para suportar os movimentos. Cidade em traveling, com cortes, planos, composições e edição nas mãos e pés do motorista privativo e sua livre circulação por caminhos predeterminados e cotidianamente cristalizados. Assim, o automóvel é outra medida a evitar o contato com as ruas, que se tornam um simples perpassar de fachadas cenográficas.
A cidade passa a ser planejada no sentido de alagar o escoamento, diminuindo as paradas: extinguindo os encontros, que passam a se resumir às sinaleiras e acidentes. $\mathrm{O}$ carro, uma casa portátil que permite conectar-se ao entorno de modo modulado e acelerado.

Não vemos mais, portanto, um jogo dialético simplificador do espaço em uma geometria bidimensional entre centro e periferia. A cidade adquire novos espaços, como os bairros não centrais e as vias de escoamento dos fluxos diários de cidadãos. As relações se complexificam e os centros concêntricos não servem como único modelo de leitura da cidade e suas dinâmicas cotidianas. $\mathrm{O}$ centro urbano permanece central no cotidiano, é certo, mas sem o status de célula civilizada. Nessa nova dinâmica, a aceleração crescente oportunizada pela lógica comercial finda por tornar o centro da cidade terra de todos, terra de ninguém: sua gravidade de buraco negro central da galáxia citadina inicia um processo de autofagia que finda em sua implosão e renascimento enquanto outro corpo urbano. Centralizam-se passagens, fluxos, e não mais moradas e encontros: da urbanidade sedentária à centralidade dos movimentos. Vazamentos de entrada e saída vão perfurar a membrana central e principiar uma inundação heterogênea. A cidade vai complexificar suas relações com a diferença, a qual tomará algumas das antigas moradas centrais, pontuando essa região de uma condição decadente antes inimaginável, a qual se justapõe a centros do poder financeiro e político.

O Hospício São Pedro nos anos 1950 já é o Hospital Psiquiátrico São Pedro (HPSP), agora medicalizado e consolidado enquanto centro de gravitação da loucura institucionalizada do estado. Seus muros alargaram-se para novas áreas longínquas chegando mesmo às cidadelas do interior do Rio Grande do Sul, mas continuam tão eretos e duros quanto antes em sua tarefa de definir uma diferenciação dos fluxos internos à instituição dos que fora desta vagueiam. Cria-se uma rede exterior a esse dispositivo central, operada principalmente por dois dispositivos: através de uma equipe de assistentes sociais subjugada ao olhar médico (não era nem permitida sua entrada no HPSP sem autorização dos psiquiatras) e parcerias com municípios do interior, ambas com o único propósito de captar e vigiar possíveis pacientes. Antes de constituir-se enquanto rede de circulação, tratase de uma rede de captura, a qual se mostra eficiente enquanto funil por onde adentraram milhares de pessoas que vieram a se institucionalizar. Com essa densificação de buraco negro, de pronto, ressurge o velho fantasma da superlotação do gigante que não suporta o próprio peso, tamanha sua densidade abissal. Dando visibilidade a essa situação, em 21 de março de 
1951, é publicada no Diário de Notícias uma matéria denunciando as condições em que vivia uma parcela da população do HPSP: "Desleixo e desumanidade Mergulho nos Abismos da Mansão da loucura", era seu título (Wadi \& Weber, 2006).

Diversas outras propostas de habitar esse espaço, por demais denso de pacientes, vão intentar modificar a situação alardeada pelos periódicos de então. Em 1943, Mário Martins e Décio Soares de Souza começaram a, de modo autodidata, tratar alguns internos do HPSP com psicoterapia. Dá-se início ao ciclo psicodinâmico do HPSP, com a formação de alguns dos seus psiquiatras em psicanálise, mais uma revolução espacial no antigo hospício:

Cabe ressaltar que o interesse em psicoterapia e higien mental desencadearia uma mudança de espaços: da instituição que isolava os doentes de seu meio, para o consultório; do psiquiatra de hospício, encarregado da contensão, ao médico compreensivo das emoções e da conduta de seus pacientes. (Zimmermann, 2002, p.23)

Algumas importantes rupturas ocorreram a partir dos anos 1950, como, por exemplo, a tomada do pátio da unidade de crônicos pelos psiquiatras. A unidade era constituída de alguns pavilhões e um pátio, os médicos se quedavam em seus consultórios, enquanto os profissionais de enfermagem levavam os internos até a presença do médico para a realização da consulta. Diante da superpopulação do hospital, tornava-se impossível dar maior atenção aos casos que se sucediam na segura sala do consultório. Assim, decidiu-se que os médicos deveriam ir com seus consultórios até o pátio para, com a aproximação, permitir seu melhor acesso às patologias dos internos (observação) e dos internos a eles (consulta). Desse modo, os médicos, enfermeiros e auxiliares a um só tempo adentraram e fizeram uso do pátio como dispositivo da clínica dinâmica (Piccinini, 2006). Uma nova medicalização do espaço, distinta da biologizante que ocorrera na primeira metade do século XX (Godoy, 1955), se vê em progresso. Um lócus antes dado aos pacientes em sua ociosidade aquém dos métodos de tratamento é considerado enquanto espaço abandonado, sendo retomado pelos psiquiatras através da observação clínica psicodinâmica.

Vemos então uma outra concepção de loucura, que exigiu outro feitio de práxis no seu tratamento: a loucura não pode, nesse momento, ser reduzida a um fenômeno orgânico, e deve ser tratada enquanto fenômeno humano, social. Assim, os jovens psiquiatras pretendem ressocializar os loucos, torná-los aptos à vida societária novamente, e, para tanto, pretendem levar o mundo para o HPSP, reproduzindo, neste, um pequeno fragmento do tecido social, de modo mais compreensivo e controlado: fazem-se festas nas unidades, leva-se um circo para o nosocômio, empreende-se um bar onde a moeda é o cigarro, intensificam-se os trabalhos com grupoterapia, praxiterapia, ambientoterapia, socioterapia. O foco do tratamento não é mais, como com Godoy (1955), somente uma ação físicoquímica ou biológica (malareoterapia, balneoterapia, insulinoterapia), mas sim uma espécie de treinamento social, em que o paciente é progressivamente exposto a estímulos e regras reproduzidos como jogos didáticos, em que tudo tem ares de faz de conta na redução das atividades e eventos a uma práxis controlada com um fim terapêutico. O HPSP é invadido pelo mundo que o circunda, mas ainda contido em si, enquanto espaço reduzido dos experimentos simplificados.

Vemos então que, assim como a cidade, o HPSP passou na metade do século XX por uma complexificação de suas geometrias disciplinares concêntricas para dar conta de uma nova dinâmica que se instalava. Enquanto a cidade centralizava fluxos e iniciava sua dispersão, as fronteiras do círculo de fechamento do São Pedro todavia permaneciam, mas deixavam entrar algo mais que pacientes ao seu interior: fissuras nesta membrana túrgida de corpos permitiam agora a entrada do mundo ao redor do HPSP, desde que esse fosse simplificado por uma redução do mesmo à clínica. Fissuras sim, mas seletivas, redutoras de complexidade: permanece algo da lógica dialética de relações entre o dentro e o fora enquanto instâncias distintas.

Assim, mesmo com tais medidas, o HPSP chega à metade da década de 1960 com a máxima superlotação de sua história: 5.500 internos. O ideário de adaptação dos pacientes por uma prática compreensiva da loucura parece ter dado de cara no próprio muro do Hospício: o mundo vinha ao hospício, mas o Hospício ainda era o mundo, e, como suas fronteiras não eram tão ágeis quanto os caminhos que até estas levavam, sua situação tornou-se de um gigantismo insustentável.

Em 1965, a Secretaria de Saúde cria um plano de reabilitação de pacientes crônicos: "Plano de Crônicos" e "Plano de Expansão dos Serviços de Assistência Psiquiátrica" (Schreen, 1997). Tais políticas seguiam o modelo da Psiquiatria Comunitária Americana, baseada no Plano "Action for Mental Health" proposto pelo governo Kennedy nos EUA. Prescrevia a criação de ambulatórios psiquiátricos junto às comunidades. No entanto, o macro-hospital permanecia enquanto referência da assistência em saúde mental. Em 1971, o HPSP passa a ter um Hospital-Dia para seus exinternos, na busca de diminuir a acachapante taxa de reingresso. No mesmo ano, o INPS lança o "Manual de serviço para a assistência psiquiátrica" (Delgado, 1997; Paulin \& Turato, 2004). O Ministério da Saúde, 
agora, incorpora o discurso que criticava suas políticas centralizadoras/tecnoburocráticas e passa a propor uma diversificação regionalizada contra o modelo do macro-hospital. Ainda assim, mesmo com um discurso voltado para uma psiquiatria comunitária, as ações do governo federal na década de 1970 apontaram para uma parceria com a Federação Brasileira de Hospitais, e a visão de montar Hospitais Psiquiátricos conveniados com o Estado (Paulin \& Turato, 2004).

Em 1973, um diagnóstico dos equipamentos de atendimento em saúde mental feito pelo Grupo de Desenvolvimento da Região Metropolitana e apresentado no Documento 21 denuncia um HPSP cronificado em sua dinâmica, exigindo amplas remodelações. Números como uma superlotação de $127 \%$ da sua capacidade, uma média de permanência de 209 dias e um índice de reinternação de 65\% são avaliados pelo documento como resultado da ausência de uma rede extra-hospitalar, situação que gera um ciclo patológico de funcionamento. $\mathrm{O}$ que se vê não é uma crítica à psiquiatria e seus modos de lidar, mas sim ao que é possibilitado aos psiquiatras a partir da configuração dos equipamentos pelos gestores. No entanto, as alterações exigidas ultrapassam a ordem médica. A reestruturação do espaço executada na década de 1970 no HPSP será um esgarçamento do processo já iniciado no ciclo comunitário-psicanalítico anterior: a invasão do HPSP pelo social. No entanto, se na década de sessenta tal âmbito era absolutamente equalizado à questão clínica, agora vemos funções gestoras, administrativas, enquanto forças ordenadoras dos fluxos.

A Secretaria de Saúde e do Meio Ambiente do RS implementou um processo que visava à ampliação do sistema de atendimento ambulatorial, à qualificação dos postos de saúde das sedes das delegacias regionais e a uma reestruturação interna da organização do espaço do HPSP. Ordenou-se a população do HPSP a partir da sua região de origem, processo possibilitado pela abertura no HPSP do Serviço Jurídico, o qual, em 1971, empreendeu uma busca jurídico-burocrática pela elucidação da situação dos internos do Hospital. Utilizaram-se os resultados desta empreitada para reordenar os corpos que lá se encontravam segundo uma definição burocrática de cultura: certidão de nascimento. Um novo instrumento de ordenação espacial se apresenta, algo diferente do saber psiquiátrico e sua nosotopologia, mas ainda com uma compreensão restrita de social a partir de uma perspectiva burocrática.

Esse primeiro processo de descentralização do HPSP durou cerca de dez anos. Inicia-se em 1971 com o Serviço Jurídico. Intensifica a setorização a partir de 1973, obtendo resultados na diminuição da população entre 1973-76. E, por fins da década de 1970 e início da de 1980, tem seu último fôlego com a instituição de uma parceria da Secretaria Estadual com o INAPS, que passaria a repassar verbas se o Hospital permanecesse com seu processo de reestruturação, no sentido de diminuir a população de 2000 internos para 500 (Barcellos, 1989). E, efetivamente, com a setorização se desospitaliza $65 \%$ dos internos, diminuindo a população de 5.500 para 1850 internos em 1982 (Schreen, 1997).

Em uma última tentativa global de esquadrinhar o seu espaço, o HPSP deixa de lado os critérios nosográficos psiquiátricos e passa a adotar critérios culturais-administrativos. Evidentemente, havia um claro ponto em que a psiquiatria se unia a esta "saúde mental administrativa", mas era exatamente no ponto onde não encontrava apoio. Os trabalhos de conclusão dos psiquiatras residentes da época usualmente se dirigiam a um tipo de tratamento individualizado, o qual não apenas não se referia em qualquer momento ao hospital psiquiátrico em sua estrutura geral como também não era realizável no HPSP de então, isso segundo os próprios proponentes das monografias e técnicos da instituição (Barcellos, 1989).

A inserção das práxis para com a loucura na cultura é a inserção da cultura na ontologia da loucura. Tanto a ontologia quanto a episteme e a práxis da loucura abrem-se para um novo campo, o qual já não pode ser reduzido à lógica medicalizante: o louco está no mundo e o mundo está no louco. As rígidas paredes da definição "loucura" sofrem nessa época algumas infiltrações que diluem o conceito em uma miríade mais complexa de relações.

Evidentemente, tais ordenações dos fluxos eram possibilitadas e ampliadas, em muito, por uma dinâmica de estratégias centradas no aspecto administrativo da loucura, o que findava por prover às ações da setorização um forte caráter burocrático: a união de pessoas com a mesma região de registro do nascimento, pouco importando se realmente viveram lá, que idades têm, e vários outros fatores étnico-culturais que seriam relevantes a uma tentativa de propiciar a construção de uma identidade grupal sociocultural. Antes de tudo, tratava-se de um esquadrinhar gestor na busca de inteligibilizar os possíveis encaminhamentos familiares e econômicos aos pacientes que estorvam a receita do Estado. Ocorre a otimização de uma prática de arquivamento, a qual passa a agrupar arquivos que serão despachados à mesma comarca e, por isso, convém estarem contidos na mesma gaveta, sob responsabilidade do mesmo escrivão. O sentido que capitaneia as estratégias 
implementadas é a transformação do macro-hospital do Estado em "hospital administrável" (Plano Diretor do Hospital Psiquiátrico São Pedro, 1980, citado por Barcellos, 1989, p.73).

A cidade e o Hospital Psiquiátrico sucumbiram na segunda metade do século XX diante da pressão da força civilizatória imposta a ambos, principalmente na primeira metade do mesmo século. Ambos não suportam as ambições impostas a eles. Não se quebraram de imediato, e, em Porto Alegre, até o início da década de 1980, não haviam adentrado por completo na fluidez. A centralidade da civilidade normal se degradou diante dos fluxos insuportáveis na aceleração que a acometeu: a superlotação e falta de verbas do HPSP e a comercialização do centro urbano da capital. Desse modo, as linhas rígidas que traçavam o mapa se esfacelaram um tanto, dando vazão a novos rabiscos que anunciam uma nova geometria: não mais central, mas dispersiva. A máquina de ressonância sofre um baque em sua centralidade equalizadora de simetrias subjetivantes. A soberania transcendente do signo civilizatório se degrada do mesmo modo que os muros do HPSP e os palacetes do centro, quedase gonza e passa a produzir anomalias normativas em suas ondas definidoras dos arranjos de forças. $\mathrm{O}$ discurso crítico ao macro-hospital é incorporado à gestão do grande Hospital psiquiátrico, e o espaço próprio à civilidade (o centro) passa a ser frequentado pelos selvagens, enquanto o espaço selvagem recebe nova camada de prédios.

\section{O cansaço da civilidade: a dispersão nômade}

Antes do final do século XX a cidade de POA baseava-se no projeto de construção de uma univocidade, baseada em uma geometria central que disciplina os fluxos em sua movimentação. Centrado a partir do que considera bom senso, o planejamento urbano do razoável insere razão e inteligibilidade no corpo da cidade e de seus cidadãos. Mas esta luta do urbanismo contra a desrazão adquire hoje outros tons: perdendo em muito a rigidez, o bom-senso e a centralidade, a cidade planejada encontrou sua derrocada. Cada vez mais, trata-se, daí em diante, de pontualmente dar conta de demandas mercadológicas locais, ou relativas ao caos urbano das constantes mudanças contingenciais no tecido citadino quanto a valorizações, deslocamentos de fluxos, zonas de risco, etc. Assiste-se à passagem da cidade planejada para a cidade negociada, na qual se desfazem, em fluido, os planos gerais da modernidade progressista: da tentativa de centralização no Estado se passa para a dispersão em projetos privados delegados então (plano e execução) a uma série de empresas, imobiliárias e empreiteiras.

Da construção de espaços de fechamento para os que fugiam aos padrões de urbanidade desejados pelos que planejavam e financiavam a cidade, para que estes últimos pudessem habitar os espaços públicos destinados à socialização dos cidadãos de respeito, passamos agora para a construção de espaços de fechamento que permitam a socialização segura no seu interior. As grades e muros deixam de ser um instrumento de aprisionamento dos fluxos no seu interior para se tornarem, em uma reversão, instrumentos de fortaleza que impedem a entrada dos fluxos externos em uma interioridade planejada para o convívio entre iguais. A autorreclusão dos iguais, ao invés do aprisionamento dos distintos, se dá com a proliferação de espaços privados e público-privados cada vez mais autônomos em sua subsistência cotidiana de serviços e lazeres. Junto a isso, a rua e o espaço público, juntamente com a simetria racional dos jardins à francesa, não somente não mais recebem os investimentos urbanizadores de antes, como passam a ser considerados espaços selvagens, selva de pedra, pela qual se transita em busca do conforto dos espaços de autorreclusão.

A configuração espacial da atualidade se contrai, implode, colapsa em uma miríade de pontos ultradensos. Assim, por exemplo, a sala de jantar de uma residência particular pode englobar um restaurante inteiro, sua cozinha, cozinheiros, a partir de uma ligação telefônica ou com um click na internet. Os espaços são cada vez mais contraídos e, por isso, cada vez mais densos. Não se trata mais do simples aproximar de distâncias em uma área em constante expansão, correspondente ao processo de concentração das cidades disciplinares. Defrontamo-nos com a multiplicação de pontos densos separados por espaços devastados, desérticos, povoados somente por velozes vias e cinzas fechadas fachadas. A operação em processo na nossa atualidade corresponde ao conceito de contração: a sobreposição dos espaços que se colocam virtualmente, de modo intensivo, disponíveis uns sobre os outros, ocupando o mesmo lugar. É a própria noção de espaço que se vê modificada, pois se trata de um espaço onde a profundidade não corresponde à terceira dimensão, mas, sim, ao virtual, ao campo dos possíveis: "Como no palco, tudo se concentra no mesmo lugar, tudo ocorre no instante privilegiado de um ato, instante [e espaço] desmesurado que substitui a extensão e as longas durações" (Virilio, 1994, p.126).

Esses espaços, densos e espessos, contemplam uma multiespacialidade e uma multifuncionalidade, o que lhes confere autonomia e a possibilidade de 
serem frequentados com o mínimo de necessidade de deslocamentos pelas vias públicas. Toda uma arquitetura de interiores é produzida e intensificada na direção do planejamento das artes de morar. Trata-se de espaços públicos, contraídos ao espaço confortavelmente privativo de uma sala de estar, onde todos se encontram sobrepostos potencialmente. Trata-se, também, de considerar que o espaço privado se expande e dilata por sobre as fronteiras do público, buscando, com seus diversos tentáculos, devorar as interações que lhe interessam. O público no privado, o público sem sair do privado. $\mathrm{O}$ mundo na sala e a sala no mundo. Pensamento acoplado aos conceitos de "onipresença planetária" (Chesneaux, 1995) e de "contração telúrica" (Virilio, 1994), ainda que seus autores privilegiem a questão temporal.

A construção destes novos guetos não é um privilégio das elites. Para além dos guetos-chics vemos a valorização da geometria labiríntica do beco pelo urbanismo contextualista (Aguiar, 2003). Tais ações visam a reproduzir os guetos menos favorecidos sem extirpá-los da malha da cidade onde se encontram e sem findar com sua autorreferência urbanística, a qual fortalece seus laços de comunidade. Essa estratégia foi utilizada em Porto Alegre na urbanização da Vila Planetário (década de 1990) e na criação do condomínio Princesa Isabel (década de 2000). Nessas experiências, quando realizadas de forma a reproduzirem de algum modo a lógica de estreitas vielas e becos autorreferidos das ocupações originais, findam por redundarem em um duplo efeito oriundo de sua conformação de gueto urbanizado enquanto gueto: por um lado, atravancam suas conexões com a cidade e afastam a circulação de todos que não pertencem à comunidade; por outro, junto desta despotencialização do espaço-passagem, vemos um reforço do uso comunitário das ruas, não somente como espaço-passagem, mas espaço de socialização (Aguiar, 2003).

$\mathrm{O}$ enunciado das estratégias espaço-temporais do espaço contemporâneo poderia, à guisa de um início de resposta, ser considerado como a aceleraçãofluidificação das vias e intensificação-privatização dos pontos em um "rizoma multipolar urbano" (Guattari, 1992). Pois, de um lado, vemos a aceleração e sutilização (info-vias) das vias segundo um imperativo do movimento em prol do lucro e da segurança no trajeto, esvaziando a rua do sentido de espaço próprio à convivência socializante. Por outro lado, vemos a criação de espaços polivalentes e bem protegidos dos fluxos do seu entorno, servindo de fortaleza ou nau em meio à tempestade do caos urbano.

Essa cidade dispersiva adensada em micropontos privativos irá se coadunar com a dissolução dos macroespaços asilares em sua crescente substituição por equipamentos dispersos pelo tecido urbano: CAPS, NAPS, ambulatórios, postos de saúde, residenciais, moradas, etc. Em conjunto com essa complexa capilarização espacial dos dispositivos de assistência mental, vemos a complexificação da sua clínica, a qual, além de também se diluir na malha urbana com o acompanhamento terapêutico (AT), dilui seu caráter clínico nas teias do social, desmedicalizando o saber que cuida do usuário. A clínica ampliada, ao invés de a tudo tornar objeto de uma clínica, de a tudo tornar passível de tratamento, passa a ser tomada por tudo, deixando de lado as reduções à clínica. O social, o comunitário, no contexto dos usuários, e a interdisciplinaridade nas equipes irão reformar a própria clínica para além de si. A clínica da Reforma busca romper suas polarizações entre clínico e político, individual e social, incorrendo em uma quebra dos limites para suas ações e definições, as quais se fragmentam nas diversas práticas sociais de administração das diferenças, adentrando nas mais íntimas esferas da vida cotidiana, com uma "visão integrada das várias dimensões da vida do indivíduo" (Secretaria Estadual da Saúde do RS, 2000, p.4).

Se na clínica da década de 1970, com o setor jurídico e a Setorização do HPSP, via-se uma abertura, controlada e burocrática, ao social como variável importante na gestão da loucura, hoje o social toma conta das práticas, com sua fluidez dispersiva que dilui a clínica em suas tramas, tornando-os híbridos incapazes de clara diferenciação. Os Direitos Humanos constituem uma nova ontologia da loucura, própria à reforma psiquiátrica contemporânea: a ontologia da loucura como entidade (processo) social (Costa, 2007).

Na Porto Alegre dos anos 1990, com a democracia já mais estabelecida no Brasil e a intensificação dos movimentos populares, o Orçamento Participativo adentra o campo da construção da cidade como uma estratégia que busca descentralizar o planejamento urbano, abrindo vias de comunicação e participação entre a prefeitura e as diversas comunidades que constituem Porto Alegre (POA). Para tanto, uma equipe de comunicação social foi a ferramenta que criou o liame entre a comunidade e a Secretaria Municipal de Planejamento. Essa ação, somada aos massivos investimentos em marketing para promover a participação, demonstra a comunicação social como fundamento de uma outra ressonância que ordenará o urbano, menos vertical e mais dispersa no território: cidade-informação.

A descentralização, operada por ferramentas de comunicação, tinha como fim a redemocratização da cidade e a inserção da política nas suas questões, 
ultrapassando tecnicismos: participação e cidadania são seus norteadores. De certo modo, é uma gestão estratégica e pontual, que admite a cidade clandestina, transbordando os esquadros do Plano Diretor. Capital e Social descentram a cidade segundo uma nova máquina de ressonância, centrada no molecular enquanto foco de suas ações moduladoras: estratégias pontuais, negociadas com agilidade, flexibilidade e rapidez.

Cidade e Hospício se esvaziam, então, de uma centralidade não somente física e geométrica, mas de uma centralidade administrativa, adentrando no mundo contemporâneo e seu imperativo de agilidade na tomada de decisões gestoras: as estratégias moleculares mostram-se mais eficientes na administração do plano urbano e da loucura do que os sonhos megalômanos dos dispositivos prioritariamente molares, e suas ideações de governos sem equívocos. Do mesmo modo, diluem-se a psiquiatria e o planejamento urbanístico, em um caos imanente de fluxos da cidade e loucura contemporâneas. O tecnicismo cientificista cede lugar a perspectivas de um gerenciamento pontual pragmático e é tomado por questões que ultrapassam o caráter científico dessas práticas, diluindo-as no Socius, onde perdem em muito suas especificidades especialistas. A gestão do Socius torna-se imperativo do que antes era compreendido como técnico-científico. Ideia de cura, que já não é cura, mas inclusão da doença e gestão da sua diferença.

\section{Uma cartografia de dois encontros: a loucura e a cidade contemporâneas}

Acompanhamos aqui o desenrolar de um longo processo de deslocamento e até reversão das lógicas disciplinares que construíram a cidade e o hospício. $\mathrm{O}$ crescente descentramento dispersivo e complexificante, a densificação dos pontos privados e aceleração das vias, a multipolarização do urbano e da assistência em saúde mental junto da transformação da gestão de ambas através do esboroamento das duras fronteiras tecno-burocráticas que delineavam um dentro e fora precisos. Essas, entre outras operações, participam hoje em dia de importantes transformações paralelas e convergentes: no urbanismo contemporâneo e na reforma psiquiátrica. A visibilização desta rede de condições de possibilidade serve, assim, para problematizar a cidade e a reforma psiquiátrica em seus rumos atuais, permitindo-nos pensar outras estratégias para intervir neste campo de tensões a partir do agenciamento entre urbanismo e clínica sem reduzir um ao outro, mas antes formando novos hibridismos entre esses.
Podemos vislumbrar esta relação entre a nova cidade e a nova clínica da saúde mental a partir da saída de Dona Murga da sua antiga morada, um espaço asilar de Porto Alegre, para uma casa em meio a um bairro residencial dessa mesma cidade. A casa se situa na esquina de um bairro residencial de classe média, bem localizada, próxima a grandes vias de circulação da cidade, mas nem tão próxima a ponto de ser devorada pelas mesmas em suas velocidades exorbitantes que só permitem o florescer de espaços comerciais. Dona Murga adentra a casa e se admira. Tudo tão diferente dos espaços-tempos asilares: a pequena sala de estar, a pequena cozinha, o pequeno banheiro, o pátio que dá obscenamente de cara com a rua. Aos poucos, com o passar dos dias e as frequentes visitas pontuais dos profissionais de saúde, Dona Murga vai ambientandose à sua nova morada. Já domina a cozinha, mexendo nos utensílios sem receios. No entanto, algo ainda a perturba.
-Aqui é muito aberto.
-Como, Dona Murga?
-Aqui é muito aberto, é o mar.
- Mar?
-É, é mar aberto, muito aberto aqui. Muito aberto. Muito aberto. Aberto. -Mas não existem aqui até mais paredes do que lá no
asilo?
-...é, he-he-he, mas é aberto, é o mar.

Os espaços-passagem que circundavam a casa flagelavam velocidade a um corpo que, de tanto ser imobilizado, se acostumara com a lentidão. Os fluxos adentravam pelas janelas em vozes-buzinas-zunidos, faziam vibrar as paredes com seu fluxo, pois essas não eram mais tão isolantes quanto as anteriores. Agora Dona Murga não estava seccionada do tecido urbano desvairado, em um espaço para insanos, autorreferido em seu esquadro de fechamento. Estava flutuando no mar da passagem urbana, náufraga em uma embarcação ainda desconhecida, mas que haveria de aprender a manejar, pois só assim poderia singrar as ondas bravias em um surf contemporâneo sem sangrar sua vida por inteiro no asfalto quente. De sua nova nau dos loucos, nossa marinheira de primeira viagem se embasbacava com as ondas que lambem o casco da embarcação a todo o momento. Agarra-se às grades e trancas para vencer o marear que já lhe embaralha o labirinto. Fecha-se na cozinha-cabine e liga alto o rádio para esquecer a tempestade. Mas também se fascina, e se joga, ainda 
que desconfiada, às correntes marinhas mais próximas, nadando por entre seus redemoinhos assistencialistas (Costa, 2007). Deve ela se domesticar, tornar-se doméstica de si, para desbravar pontualmente o mar, mas ter na nau seu porto seguro, ou deve ela tornar-se corsária e seguir errante em suas experimentações de insana que tanto amedrontam os profissionais gestores da loucura? Vemos aí o quão complexa é a intersecção de dois heterotopos (o hospício como espaço de fechamento e a rua como espaço de passagem) em um acontecimento como o protagonizado por Dona Murga na construção do seu lar nesta nova cidade multipolar.

Desse modo, podemos ver a casa como um rastro de resto de esquadro diante da fluidez flexível da rua da cidade em sua passagem constante, um ínfimo ordenar que se põe, como uma nau em meio à tempestade permitindo um território existencial. Do mesmo modo, podemos vê-la como masmorra domiciliar, prisão doméstica erguida pelo medo do outro que não está identitariamente definido pelas paredes do nosso lar, pela paranoia lancinante da barbárie urbana com sua horda sempre do lado de fora, de tocaia a esperar um deslize nosso.

O desvio de olhar, o passar reto, o insu film com ar-condicionado, a reclusão em "prisão" domiciliar, tornam possível, assim, a coexistência no meio urbano: coexistência da indiferença garantida nas microblindagens ao encontro. Dona Murga enfrentará o desafio de encontrar-se com os outros nesta nova urbanidade apressada e amedrontada, terá o desafio de ir além das redes emaranhadas da saúde mental e seus dispositivos de assistência, de transbordar sua vida para além destes novos muros urbanos. Desse modo, nessa mesma cidade de Porto Alegre da qual tanto já falamos, assistia eu ao pôr do sol no Guaíba através do para-brisa do meu carro, parado em um largo estacionamento, ao lado de um centro cultural revitalizado ligado a uma grande via perimetral. Fazia frio e vento, assim, permaneci no interior do automóvel, utilizando-o como escritório móvel, o qual eu podia alocar na cidade segundo o meu desejo de paisagem. Escrevia sobre as novas segmentações da loucura, preparando este artigo, quando uma garotinha portadora de alguma síndrome que se fazia visível em suas feições bateu ao meu vidro fechado. Atazanado que me encontrava na tarefa, e liso de moedas como estava, simplesmente lhe sinalizei com um gesto que não tinha nada a dar. No entanto, a menina insistiu que abaixasse meu vidro, e me estendia um papel. Vendo que não surtira efeito minha tática de fuga, abri o vidro, pronto a apanhar um papel que contivesse um dos tantos pequenos grandes dramas que salpicam nossas cidades. Ainda tentei explicar-lhe outra vez, antes de mirar o papel, que não tinha qualquer coisa a oferecer para sanar sua fome e aplacar minha culpa. No entanto, ela esticou seu pequeno braço e falou com uma dicção confusa: "é um convite". Estranhado, finalmente peguei o pequeno bilhete e levei aos olhos; nele estava escrito: "muito obrigado pelo teu olhar".

\section{Referências}

Aguiar, D. V. (2003). Colisões urbanas: continuidades e descontinuidades. Arquitextos, 166. Acesso em 23 de junho, 2006, em http://www.vitruvius.com.br/arquitextos/arq000/ esp166.asp

Barcellos, D. M. (1989). Políticas de saúde mental e a organização do hospital público no Rio Grande do Sul. Dissertação de Mestrado, Programa de Pós-graduação em Antropologia Social, Universidade Federal do Rio Grande do Sul, Porto Alegre.

Carvalho, H. L. (1996). A modernização em Porto Alegre e o Majestic hotel. In Prefeitura Municipal de Porto Alegre, Porto Alegre: dissertações e teses (pp. 65-72). Porto Alegre: Unidade Editorial.

Chesneaux, J. (1995). Modernidade Mundo. Rio de Janeiro: Vozes.

Costa, L. A. (2007). Brutas cidades sutis: o espaço tempo da diferença na contemporaneidade. Dissertação de Mestrado, Programa de Pós-graduação em Psicologia Social e Institucional, Universidade Federal do Rio Grande do Sul, Porto Alegre. Acesso em 05 de agosto, 2008, em http://hdl. handle.net/10183/13404

Delgado, P. G. G. (1997). Perspectivas da psiquiatria pós-asilar no Brasil. In N. R. Costa \& S. A. Tundis (Orgs.), Cidadania e loucura: Políticas de saúde mental no Brasil (pp. 104-120). Petrópolis, RJ: Vozes.

Faculdade de Arquitetura da UFRGS- FACARQ. (1980). Urbanização de Porto Alegre. Porto Alegre: Ed. UFRGS.

Godoy, J. (1955). Psiquiatria no Rio Grande do Sul. Porto Alegre: [s.n.].

Guattari, F. (1992). Caosmose: um novo paradigma estético. Rio de Janeiro: Ed. 34.

Paulin, L. F. \& Turato, E. R. (2004). Antecedentes da Reforma Psiquiátrica no Brasil: as contradições dos anos 1970. História, Ciências, Saúde, 11(2). Acesso em 15 de julho, 2007, em http://www.scielo.br/scielo.php?pid=S0104$\underline{59702004000200002 \& \text { script }=\text { sci arttext }}$

Piccinini, W. J. (2006). Momentos da história da psiquiatria. Psychiatry on line Brazil, 11. Acesso em 15 de julho, 2007, em http://www.polbr.med.br/wal0206.htm

Schreen, H. I. (1997, janeiro). A reforma psiquiátrica no Rio Grande do Sul: história da assistência em saúde mental e situação atual. Revista de Psiquiatria do RS, 19, 8-15.

Secretaria Estadual da Saúde do RS. (2000). Projeto Morada São Pedro: implantação serviços residenciais terapêticos. Porto Alegre: Estado do Rio Grande do Sul.

Sevcenko, N. (1998). A capital irradiante: técnica, ritmos e ritos do Rio. In N. Sevcenko (Org.), História da vida privada no Brasil, Vol. 3. República: da belle époque à era do rádio. (pp.513 - 619). São Paulo: Companhia das Letras.

Virilio, P. (1994). O último veículo. Revista 34 Letras, 5-6, 3848.

Wadi, Y. M. \& Weber, N. M. (2006). O Doutor Jacintho Godoy e a história da psiquiatria no Rio Grande do Sul /Brasil. Nuevo 
Mundo Mundos Nuevos, 6. Acesso em 12 de setembro, 2006, em http://nuevomundo.revues.org/document1556.html

Zimmermann, J. J. (2002). Do hospício ao divã: a história da psicanálise no Rio Grande do Sul de 1928 a 1963. Revista de Psiquiatria do RS, 24(3), 296-304.

Recebido em: 19/10/2009

1a. Revisão em: 30/05/2010

2a. Revisão em: 27/06/2010

Aceite em: 14/07/2010

Luis Artur Costa é Docente adjunto do Curso de Psicologia da UFPel, Doutor do PPGIE UFRGS. Mestre em Psicologia Social e Institucional na Universidade Federal do Rio Grande do Sul. Endereço: Avenida Duque de Caxias, 250 Fragata. Pelotas/RS, Brasil. CEP 96030-001. E-mail: nemseiquem@gmail.com

Tania Mara Galli Fonseca é Professora no PPG em Psicologia Social e Institucional UFRGS e no PPG de Informática Educacional UFRGS. Coordenadora do grupo Modos de Subjetivar.

E-mail: tfonseca@,via-rs.net

\section{Como citar:}

Costa, L. A. \& Fonseca, T. M. G. (2013). Cidades sutis: dispersão urbana e da rede de saúde mental. Psicologia \& Sociedade, 25(n. spe. 2), 21-30. 